\title{
19.1
}

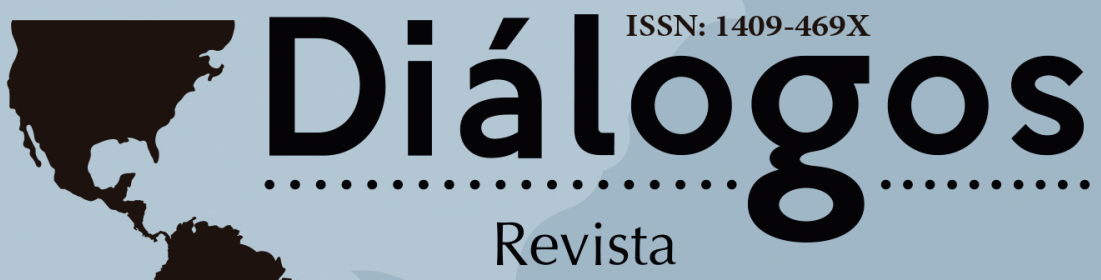

Electrónica de Historia

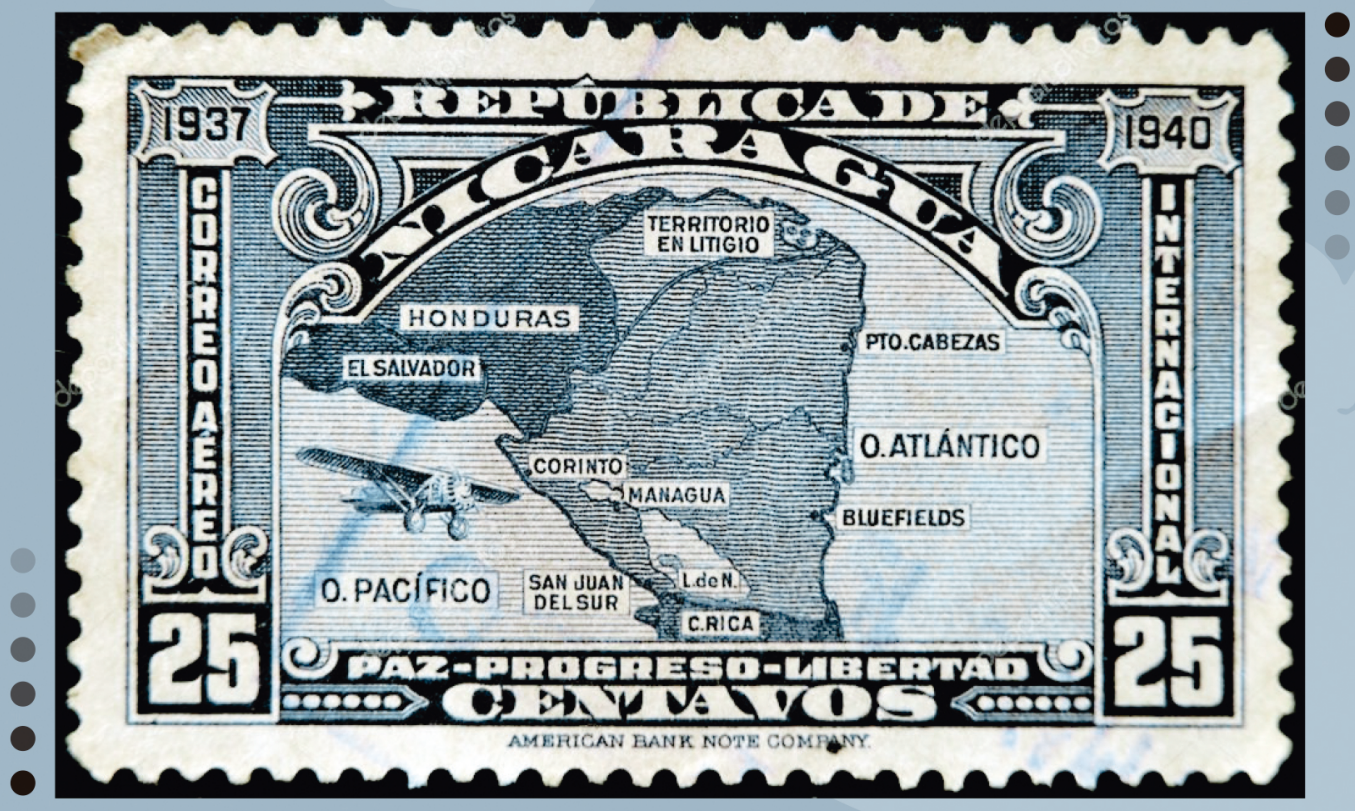

Escuela de Historia. Universidad de Costa Rica

\section{Enero-junio 2018}

url: http://revistas.ucr.ac.cr/index.php/dialogos/index

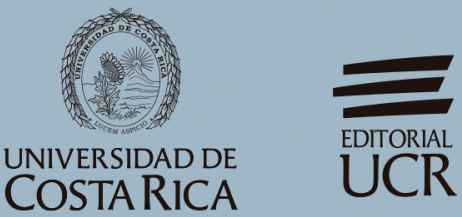




\section{RECETAS CONTRA EL CONJURO: LOS \\ ESTILOS DE DESARROLLO EN EL URUGUAY \\ CONTEMPORÁNEO Y LOS DEBATES SOBRE EL \\ DESARROLLO LATINOAMERICANO (1973-2014)}

Sebastian Levalle

\section{Resumen}

Desde el comienzo de la década de 1950, el Secretario General de la CEPAL, Raúl Prebisch, alertó sobre el deterioro de los términos del intercambio que afectaba a los países del subcontinente. Lo anterior en función del mayor crecimiento de la demanda de productos manufacturados importados con respecto a la de bienes primarios a exportar. El aporte prebischeano prefiguró una serie de debates que en las ciencias sociales latinoamericanas comenzaron a darse en los años 1960/70. En dichos intercambios se sedimentó un conjunto de conceptos explicativos de la realidad latinoamericana que en los trabajos posteriores fueron relegados a un segundo plano. Frente a esta amnesia recurrente en el pensamiento de dichos países, se cree pertinente analizar los principales estilos de desarrollo del Uruguay entre 1974 y 2014. Se llevará a cabo este trabajo recuperando aquellos debates fundantes de las ciencias sociales latinoamericanas. En primer lugar, se analizará la configuración de un estilo de desarrollo dependiente, concentrador y excluyente desde 1973 hasta el 2004. En segunda instancia, se estudiarán las características de las políticas económicas y sociales implementadas por los gobiernos del Frente Amplio (2005-2014).

Palabras claves: Uruguay, desarrollo económico y social, América Latina, marxismo, estructuralismo.

Sebastian Levalle - Licenciado en Sociología por la Universidad de Buenos Aires y maestrando en Estudios Sociales Latinoamericanos en la misma casa de estudios. Becario doctoral del CONICET y auxiliar docente en Principales Corrientes del Pensamiento Contemporáneo en la Facultad de Ciencias Sociales de la Universidad de Buenos Aires, así como jefe de trabajos prácticos en Sociología General y Contemporánea en la Universidad Nacional de José C.Paz. Contacto: slevalle@yahoo.com.ar 


\title{
RECIPES AGAINST THE CONJURY: DEVELOPMENT STYLES IN CONTEMPORARY URUGUAY AND THE DEBATES ON LATIN AMERICAN DEVELOPMENT (1973-2014)
}

\begin{abstract}
Since the beginning of the 1950s, CEPAL Secretary-General, Raúl Prebisch, warned of the deterioration in terms of trade affecting the countries of the subcontinent. The contribution Prebisch made to the message of industrialization prefigured a series of debates that Latin American social sciences would begin to emerge in the 1960s and 1970s. In these exchanges emerged a set of explanatory concepts of the Latin American reality that in the later works were relegated to a second plane. Faced with this recurrent amnesia in the thinking of our countries, it is pertinent to analyze the main styles of development of Uruguay between 1974 and 2014. This work will be caring on by restoring those foundational debates of the Latin American social sciences. In first place, this article aims to analyze the configuration of a style of dependent development from 1973 to 2004. The second main point pretends to examine the characteristics of the economic and social policies implemented by the Frente Amplio governments (2005-2014).
\end{abstract}

Keywords: Uruguay, economic and social development, Latin America, Marxism, structuralism. 


\section{INTRODUCCIÓN}

Desde la creación de la Comisión Económica para América Latina (CEPAL) en la segunda posguerra mundial y el famoso discurso del entonces presidente de Estados Unidos, Harry Truman, en 1948 la temática del desarrollo conquistó el campo intelectual continental. Los teóricos del desarrollo, fuertemente influenciados por los postulados modernizantes de las ciencias sociales estadounidenses, se propondrán conjurar el "atraso" latinoamericano mediante el impulso a la industrialización y la planificación estatal. En tales propuestas el desarrollo era concebido como una sucesión de avances en la linealidad del progreso (Guddynas y Acosta, 2011). La teoría del desarrollo resultaba un alegato a favor de la adopción de la racionalidad económica moderna y consideraba a la sociedad europea y estadounidense como un ideal a alcanzar.

No obstante, desde el comienzo de la década de 1950, el Secretario General de la CEPAL, Raúl Prebisch, alertó sobre el deterioro de los términos del intercambio que afectaba a los países del subcontinente. Lo anterior, en función del mayor crecimiento de la demanda de productos manufacturados importados con respecto a la de bienes primarios a exportar. El enfoque histórico-estructural de la CEPAL se orientaba hacia la comprensión de las especificidades de la inserción latinoamericana en el mercado mundial, habilitando una mirada integrada sobre el desarrollo (Bielschowsky, 2010). Según Prebisch, los trabajadores latinoamericanos no lograban beneficiarse de la caída de los precios derivada del aumento de la productividad en la producción de manufacturas en el centro. La existencia en América Latina de un exceso de mano de obra y de una gran cantidad de sectores pre-capitalistas de baja productividad, imposibilitaba la retención de los frutos del progreso técnico por parte de los países subdesarrollados. De este modo, el conjuro del subdesarrollo que azotó a nuestra región apareció como resultado del proceso sociohistórico latinoamericano.

El aporte prebischeano al mensaje de la industrialización prefiguraba una serie de debates en las ciencias sociales latinoamericanas que permearían fundamentalmente en dos espacios uruguayos: la Comisión de Inversiones y Desarrollo Económico y el semanario Marcha. En dichos intercambios se sedimentaría un conjunto de conceptos explicativos de la realidad latinoamericana que en los trabajos posteriores fueron relegados a un segundo plano. Frente a esta amnesia recurrente en el pensamiento de nuestros países, se cree pertinente analizar los principales estilos de desarrollo del Uruguay entre 1974 y 2014, partiendo desde aquellos debates fundantes de las ciencias sociales latinoamericanas. Para ello se presentarán los clivajes centrales de los debates latinoamericanos sobre el desarrollo, para después adentrarse en la descripción de los estilos de desarrollo en el Uruguay a partir de una periodización en dos tiempos. En primer lugar, se analizará la configuración de un estilo de desarrollo dependiente, concentrador y excluyente desde 1973 hasta el 2004. Después, se estudiarán las características de las políticas económicas y sociales implementadas por los gobiernos del Frente Amplio (2005-2014). 
En cada uno de los períodos señalados, se intentará dar cuenta de la evolución de las variables económicas que caracterizan los estilos de desarrollo y de los debates que se suscitaron alrededor de ellos. A tono con los debates de los años 1960/70 se preguntará: ¿Cuáles fueron las características fundamentales del estilo de desarrollo en cada período?, ¿De qué modo se modificó la inserción uruguaya en el mercado mundial?, ¿Qué sectores económicos explican el crecimiento?, ¿Cómo evolucionó la heterogeneidad estructural?, ¿Cuál fue el impacto del estilo de desarrollo implementado sobre la configuración de la estructura social? ¿Cómo se (re)distribuyeron los excedentes?, ¿De qué forma se relacionó la evolución económica uruguaya con el conjunto de la región?, ¿Qué elementos están presentes en el debate contemporáneo y cuáles permanecieron en el olvido?

\section{AVIONES QUE NO DESPEGAN: LAS CRÍTICAS LATINOAMERICANAS AL DESARROLLO DURANTE LAS DÉCADAS DE 1960/70}

El ataque a la política de industrialización en gran parte de las dictaduras militares de los años 1970 en el Cono Sur resultaba una expresión de las orientaciones económicas impulsadas por los países centrales para las economías periféricas tras el debilitamiento del keynesianismo. Pero, al mismo tiempo, el proceso de sustitución de importaciones se enfrentaba a un conjunto de desafíos de difícil solución. Estos desafíos nutrieron los debates de las ciencias sociales latinoamericanas de su materia prima, alimentando una serie de críticas al modelo modernizador del desarrollo. Estas críticas pueden agruparse a grandes rasgos en dos tendencias que han hecho mella en la escuela latinoamericana: la reformista-estructuralista y la marxista-revolucionaria. A pesar de sus diferencias, ambas corrientes critican la teoría de la modernización, definen el subdesarrollo como el resultado del capitalismo y consideran que los países subdesarrollados poseen particularidades propias (Kay, 1991).

Desde los años 1950, la CEPAL se preocupó por comprender la estructura social latinoamericana sentando las bases de la corriente reformista-estructuralista. Celso Furtado (1973) fue uno de los primeros estructuralistas en llamar la atención sobre la concepción temporal errónea en la que se basaban los desarrollistas "clásicos". Contra la idea de emular los procesos de "despegue económico" de las economías centrales presente en análisis como los de Walt W. Rostow (1961), el brasilero planteó la irreversibilidad del tiempo mundial. Dada su incorporación al mercado mundial como proveedora de materias primas y su carácter de importadora de tecnología, América Latina mostraba una estructura dual y desarticulada.

Por su parte, Aníbal Pinto (1970) acuñó el concepto de heterogeneidad estructural para hacer referencia a estas disparidades de productividad entre estratos productivos que se manifestaba en las economías latinoamericanas. Pinto planteaba que en sociedades estructuralmente heterogéneas la propuesta modernizante de 
irradiar el progreso desde el foco modernizador hacia el interior demostraba su fracaso. Según Pinto el sector moderno no lograba desplegar el efecto homogeneizador esperado por los desarrollistas con lo cual la industrialización latinoamericana contribuía a aumentar la heterogeneidad estructural. Pinto explicaba esta aparente paradoja en función de la autonomía del sector industrial, cuestión que se derivaba de la orientación de la industria hacia la demanda de los sectores de altos ingresos. Según el autor chileno, este tipo de industrialización tiene un crecimiento limitado, demanda mucho capital, y requiere una capacidad empresarial altamente calificada y un alto componente importado que impacta negativamente en la balanza comercial.

La segunda corriente crítica del modelo modernizador de desarrollo estuvo inspirada en el marxismo. Los críticos marxistas cuestionaron las tesis dualistas del paradigma modernizador que concebían a las sociedades latinoamericanas como compuestas por un sector tradicional de baja productividad y un sector moderno y dinámico vinculado al mercado mundial. Rodolfo Stavenhagen (1965) argumentaba que antes que una economía desarticulada, la situación de los países periféricos mostraba una compleja interrelación entre sus estructuras económicas. Las áreas subdesarrolladas resultaban fundamentales para el desarrollo del sector moderno ya que lo proveían de mano de obra barata y de materias primas, configurando una situación que Pablo Gonzalez Casanova (1963) denominó “colonialismo interno". Desde esta perspectiva, André Gunder Frank (1967) intentaba comprender el modo en el que el desarrollo genera -y necesita del- subdesarrollo.

Rápidamente, el subdesarrollo fue ligado a la situación de dependencia de los países latinoamericanos respecto de los países centrales o hegemónicos. Según Theotonio dos Santos (1998: 6), la teoría del desarrollo respondía a las ansias de las burguesías locales de aumentar su participación en el mercado mundial, mientras que la teoría de la dependencia buscaba comprender críticamente las limitaciones histórico-estructurales para el desarrollo latinoamericano. El abordaje estructuralista de la dependencia tomará una nueva dimensión con la publicación en 1967 de "Desarrollo y dependencia en América Latina" de Fernando Enrique Cardozo y Enzo Faletto. En su vocación de establecer un análisis integrado del desarrollo nacional, los autores ponen en relación las estructuras sociopolíticas internas y la internacionalización capitalista para determinar las situaciones concretas de dependencia. Así, la dependencia resultaba un fenómeno externo e interno que se expresaba como un modo determinado de relaciones estructurales (Cardozo y Faletto, 2003). Cardozo consideraba que bajo la dependencia era posible el desarrollo, por eso acuñó el concepto de "desarrollo dependiente", distanciándose de la idea de "desarrollo del subdesarrollo" planteada por Frank (Kay, 1991)

Quien fuera el teórico marxista más importante de la dependencia, Ruy Mauro Marini, avanzó en el estudio de las relaciones entre dependencia y heterogeneidad estructural. Según el economista y sociólogo brasileño, el aumento de la productividad de las economías imperiales se sustenta en una mayor explotación del trabajo en los países dependientes. Mientras que en los primeros la acumulación se basa en la 
producción de plusvalía relativa, los segundos se orientan a la extracción de plusvalía absoluta (Marini, 2008a: 123). Por lo tanto la división internacional del trabajo implicó para estos países un modo de producción basado en la superexplotación del trabajo que opera aumentando su intensidad, prolongando la jornada, y reduciendo el consumo del obrero más allá de su límite normal. Es esta cualidad intrínseca de las economías latinoamericanas la que explica el fracaso de la industrialización. Los bajos salarios inherentes al patrón de acumulación de los países dependientes deprimen la demanda interna, acotando el mercado al consumo de los sectores de altos ingresos. El punto fundamental de la argumentación de Marini consiste en señalar que la realización del valor en el capitalismo depende en última instancia de la superexplotación del trabajo. En este sentido, la dependencia, que opera como un modo de captar el valor que se produce en las economías oprimidas, es inescindible del comportamiento del sistema capitalista.

Por otro lado, el enfoque estructuralista cepalino fue conocido en Uruguay en los cursos de Economía Política II que dictaba el profesor Luís Faroppa en 1950 (Bittencourt, Galván, Moneira y Vázquez, 2012). Uno de los estudiantes de esos cursos fue Enrique Iglesias. Diez años después, este contador sería el director de la Comisión de Inversiones y Desarrollo Económico (CIDE). La CIDE fue el primer organismo planificador del Uruguay, cuyo objetivo consistía en formular planes orgánicos de desarrollo económico. Dicho propósito se materializó en el primer "Plan Nacional de Desarrollo", un amplio programa de reformas estructurales (Garcé, 2002). Este organismo estuvo fuertemente influenciado por la CEPAL y por la Alianza para el Progreso surgida en Punta del Este en agosto de 1961. La Alianza para el Progreso representó una estrategia del gobierno estadounidense de John F. Kennedy para desalentar la opción socialista que la revolución cubana había inaugurado en América Latina. Su propósito declarado consistía en aunar esfuerzos entre los Estados Unidos y los países latinoamericanos para lograr el progreso continental mediante la planificación estatal y una serie de reformas económicas y sociales.

El modelo de planificación que se proponía la CIDE era concebido como una estrategia reformista dentro de la economía de mercado que apelaba a una legitimación de corte técnica, racional y objetiva. Sus vínculos con el sector empresarial fueron estrechos, especialmente desde el surgimiento de la Comisión de Coordinación para el Desarrollo Económico, organismo de las instituciones empresariales, aunque también se articuló con las organizaciones sindicales, bajo una idea de "economía concertada" (Garcé, 2002).

En 1963 la CIDE llevó a cabo un "Estudio económico del Uruguay", que constituyó el primer diagnóstico de la situación económico-social del país. Un año después, a instancias del Poder Ejecutivo, el organismo elaboró el Plan de Desarrollo, que incluía reformas económicas y sociales, entre las que se contaban modificaciones en las formas de tenencia de la tierra, planes de promoción industrial, un plan de educación y otro de vivienda. Sin embargo, las recomendaciones 
del Plan de Desarrollo fueron escasamente adoptadas por los gobiernos sucesivos y en 1967 la CIDE fue desarticulada.

Contra el imaginario modernizante y reformista del desarrollo que encarnó la CIDE, el semanario Marcha se constituyó como espacio de difusión de un conjunto de propuestas que articulaban el desarrollo uruguayo con la integración latinoamericana y con el imaginario antiimperialista que había instalado la experiencia Cubana. Tribuna de crítica cultural y política, este semanario reunió a intelectuales de diversas procedencias que pugnaban por un "verdadero desarrollo", alejado de los preceptos panamericanistas de la Alianza para el Progreso. Ximena Espeche Gilardoni (2010) sostiene que el debate de ideas que tomó cuerpo en Marcha se nutrió de la crisis estructural atravesada por el Uruguay hacia mediados del siglo XX. Esta crisis configuró el escenario para cuestionar la imagen de la "excepcionalidad uruguaya" forjada después del segundo gobierno de José Batlle y Ordóñez. El destino del país, según intelectuales como Carlos Quijano, estaba indefectiblemente ligado al devenir de la región latinoamericana: "no habrá desarrollo sin integración" (Quijano, citado en Espeche Gilardoni: 2011, p. 195). La integración aparecía entonces como condición para superar la dependencia uruguaya.

El debate sobre la dependencia y los obstáculos al desarrollo en América Latina fue también un debate sobre el carácter de las burguesías locales. Los estructuralistas sostenían que en Latinoamérica el desarrollo, entendido como la creación de una estructura productiva homogénea capaz de asegurar la distribución igualitaria del excedente, se había alcanzado históricamente en situaciones de alianza entre una burguesía industrial nacional y la clase trabajadora. Tal proyecto histórico nacional era identificado con los gobiernos de Lázaro Cárdenas en México, Juan Domingo Perón en Argentina y Getulio Vargas en Brasil. Contrarios al enfoque nacional que proponían los estructuralistas, los autores identificados con el marxismo -como Stavenhagen, Marini o Agustín Cueva- pensaban que las burguesías latinoamericanas no tenían un interés nacional ni profesaban valores democráticos. Por el contrario, en estos análisis se planteaba que los sectores industriales se identificaban con el capital transnacional. Stavenhagen (1965) advertía que las burguesías latinoamericanas no se distinguían claramente de los grupos terratenientes con quienes compartían negocios e intereses, por lo que no resultaba factible pensar en una disputa al interior de las clases dominantes en los términos en los que esta contienda se desarrolló en Europa. Desde esta perspectiva no había lugar para una revolución democrático-burguesa en América Latina, ni tampoco podía esperarse un verdadero desarrollo mientras persistiera la dependencia. Se imponía entonces para estos intelectuales el camino socialista como única salida a los problemas de la industrialización dependiente.

Parece haber existido cierto consenso entre los diversos autores acerca de la existencia de fuertes impedimentos para la articulación de la alianza desarrollista en la América Latina de los años 1970. Cardoso y Faletto (2003, p. 151) afirmaban que en los casos de desarrollo dependiente con fuerte presencia de capitales extranjeros el desarrollo, sólo puede sostenerse intensificando la exclusión y la marginalización 
social. Por lo tanto, para estos autores, en las condiciones estructurales latinoamericanas de los años 1970 el desarrollo dependiente tendía hacia los regímenes corporativos-autoritarios. Incapaces de construir su propia hegemonía y temerosas de perder su poder frente al ascenso de la movilización popular, las burguesías impulsarán en varios países latinoamericanos una serie de golpes de Estado con el objetivo de aumentar su participación en la distribución del excedente.

\section{DESARROLLO DEPENDIENTE, CONCENTRADOR Y EXCLUYENTE EN URUGUAY: LAS POLÍTICAS NEOLIBERALES Y EL OLVIDO DE LOS DEBATES DE LAS CIENCIAS SOCIALES LATINOAMERICANAS (1973-2004)}

\section{El olvido impuesto: las políticas neoliberales durante la última dictadura militar y la transición democrática (1973-1990)}

El diagnóstico de la dictadura uruguaya que llega al poder en 1973, planteaba que el estancamiento económico que atravesaba el país se debía a las fuertes transferencias de ingresos hacia el sector industrial y sobre todo a la esfera estatal, particularmente hacia los empleados públicos. Esta lectura de la realidad económica uruguaya se impondrá por medio de las armas, sentenciándose al olvido los debates de las ciencias sociales latinoamericanas y regresando a la vieja fórmula ricardiana que propone la especialización productiva en función de las ventajas comparativas. En 1974 el gobierno militar clausuró el semanario Marcha, acabando con un espacio que articuló otras formas de pensar el desarrollo y la integración internacional uruguaya. El gobierno dictatorial impulsó una economía de tipo agroindustrial exportadora con el objetivo de posicionarse competitivamente en el mercado internacional.

Como señalan Luis Bértola y Gustavo Bittencourt (2005), ya no se apuntaba a la sustitución de importaciones, sino a agregar valor a las exportaciones de bienes primarios. Las primeras medidas económicas confirman esta dirección: ley de promoción de inversiones, reducción de la restricción a las importaciones, promoción de nuevos rubros de exportación mediante subsidios, reintegros, créditos, etc. (Bértola y Bittencourt, 2005, p. 311). Otro de los objetivos primordiales en este período fue posicionar al Uruguay como una plaza financiera regional, situación que requirió de la liberalización del tipo de cambio y las tasas de interés. En este contexto, tuvo un gran protagonismo el ingreso del capital extranjero, ocasionando graves consecuencias en el crecimiento de la deuda externa. Como evidencia Yafee (2010, p. 6), "el endeudamiento pasó de US\$ 1240 millones en 1978 a US\$ 3129 millones en 1981, representando $25 \%$ y $28 \%$ del PBI respectivamente". Por otro lado, la gran mayoría de este capital no fue invertido en el sector productivo, sino volcado al consumo privado y la especulación, lo cual a su vez permite explicar el 
considerable aumento de los niveles de importaciones. Recuperando los aportes de la teoría de la dependencia se puede afirmar con Santos (1998, p. 12) que este tipo de crecimiento económico representa un desarrollo dependiente asociado al capital internacional, con un fuerte matiz concentrador y excluyente (Santos, 1998, p. 12).

Dentro de estas generalidades, la política económica de la dictadura tuvo diferentes expresiones. En un primer momento, el gobierno militar decidió sostener el “Plan de Desarrollo 1973-1977", elaborado por la Oficina de Planeamiento y Presupuesto durante el gobierno del colorado Juan María Bordaberry. Este plan proponía un proceso de liberalización en todos los planos de la economía nacional. Luego, la designación de Vegh Villegas como Ministro de Economía y Finanzas, inauguró un momento que es caracterizado por Jorge Notaro (2010:34) como "intervencionismo reestructurador", ya que se implementó una política de promoción de exportaciones industriales con base a bajos salarios y facilidades impositivas y crediticias. Este economista uruguayo identifica un tercer momento en la política económica desplegada por la última dictadura militar, al que denomina "liberalismo estabilizador", cuya nota sobresaliente es la preocupación por la estabilización de los precios y que se extendió entre 1978 y 1982.

$\mathrm{Al}$ inicio de la dictadura el país retomó una fase de crecimiento económico. Bértola y Bittencout (2005: 326) adjudican este resultado a la caída de los salarios habilitada por el poder represivo de la dictadura -que puede apreciarse en la Figura 1- y por la eliminación de los sindicatos. El crecimiento se detendrá con la crisis de 1982/84, en el contexto de la crisis de la deuda latinoamericana. Los planes de estabilización monetarios basados en "anclas cambiarias" determinaron una sobrevaloración de

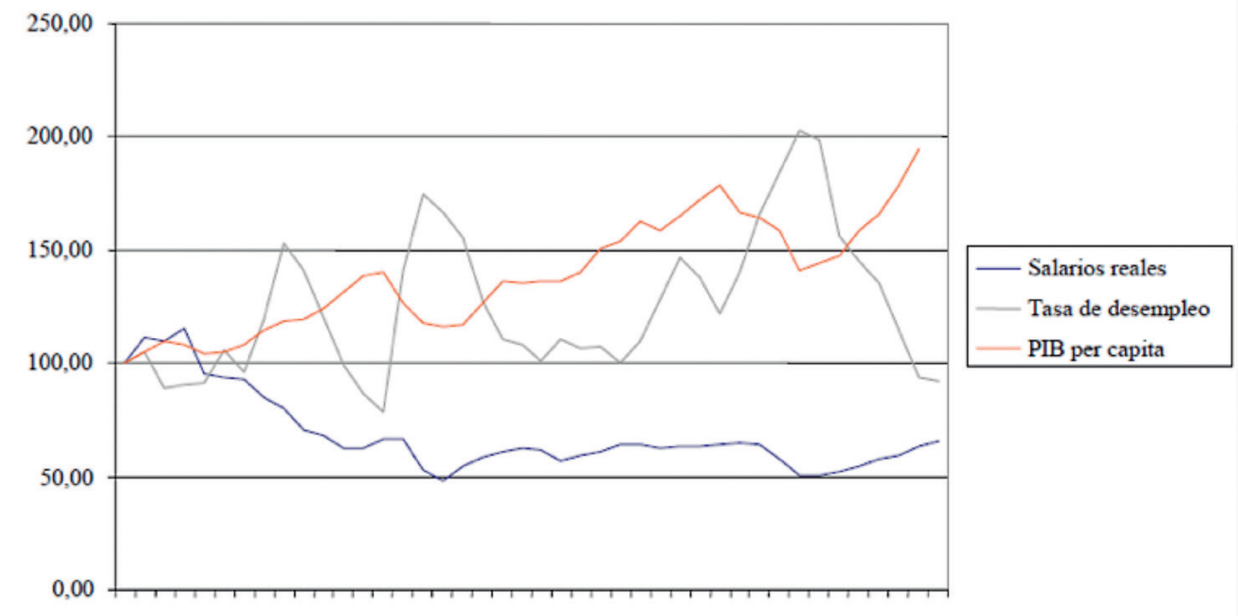

19681971197419771980198319861989199219951998200120042007 
la moneda, mientras que la aplicación de políticas fiscales expansivas y la caída de la recaudación tributaria implicaron crecientes desequilibrios fiscales. La crisis de 1982/84 fue una "crisis múltiple": de balanza de pagos, bancaria, fiscal, productiva y social (Antía, 2004: 1). La recuperación de esta crisis fue lenta, recién en 1985 se registró un leve aumento del PBI y hasta 1986 no hubo una recuperación apreciable.

En 1985, con la recuperación de la democracia, se inaugura un período fértil de debate en torno a la política económica uruguaya. No obstante, el clima de época ya era otro. La teoría de la dependencia había sufrido una serie de críticas que iban desde el monetarismo en boga hasta el marxismo ortodoxo en retirada. Las experiencias de "despegue" económico de los países del sudeste asiático eran interpretadas como la refutación empírica de los obstáculos para el desarrollo de los países latinoamericanos, desconociéndose las particularidades de aquellos casos (Santos, 1998). La crisis de la deuda latinoamericana había alterado las prioridades de la CEPAL que ahora abandonaba la mirada de largo plazo para atender los problemas macroeconómicos (Bielschowsky, 2010). Los países periféricos volvían a confiar en el desarrollo modernizador. Tal como afirma Fernanda Beigel (2006: 303), “[e]l eje del debate en las ciencias sociales se desplazó de la preocupación por el cambio estructural hacia el tema del orden y la convivencia democrática". Por eso no sorprende que más allá de la breve etapa de recuperación de 1985-1987 en Uruguay no pudiera consolidarse un nuevo modelo de desarrollo. La política económica de la dictadura arrojó algunos elementos que continuarían vigente en lo sucesivo: la hegemonía del capital financiero, la facultad del Poder Ejecutivo para fijar los precios y los salarios y la libertad internacional de movilidad del capital y del mercado cambiario (Notaro, 2010). Si bien desde 1978 se promovió una mayor apertura económica, en rigor la política económica de este período no siguió al pie de la letra los mandatos del neoliberalismo -no se avanzó con una política de privatizaciones, por ejemplo-; antes bien, durante la dictadura se preparó el terreno para el despliegue de un modelo neolibaral en las décadas posteriores (Falero, 2011: 137).

\section{La amnesia recurrente: La consolidación del neoliberalismo en democracia (1990-1998)}

Para el conjunto de América Latina, la década del noventa marcó el inicio de un período de profundización de las llamadas "reformas estructurales" que habían comenzado a gestarse desde fines de los años setenta y que fueron especialmente promovidas por organismos financieros internacionales (Fondo Monetario Internacional (FMI), el Banco Mundial (BM) o el Banco Interamericano de Desarrollo (BID). Al respecto, Bittencourt (2006: 16) señala que la mayor de las reformas se basó en la liberalización comercial, "que en teoría aspiró a que la economía abandonara la pretensión proteccionista y se orientara a especializarse de acuerdo con las ventajas comparativas que llamaremos estáticas, por cuanto se apoyan en los recursos existentes 
en una economía". En el caso de la región, esta variable se relaciona directamente con los recursos naturales, lo que llevó a la mayoría de los países latinoamericanos a especializarse en agroindustrias, productos mineros y petroquímicos. Las recetas instrumentadas por el llamado Consenso de Washington dominaron la agenda económica de la región. A la apertura externa se sumaba la liberalización y la desregulación de los mercados y la privatización de empresas y servicios públicos.

Tal como afirma Sunkel (2007: 470), se trata de una etapa en la que el desarrollo, "que se había concebido como una tarea prioritaria de largo plazo a ser impulsada fundamentalmente desde la esfera estatal, fue reemplazado por una preocupación prioritaria respecto de la estabilidad monetaria y financiera." En Uruguay la política económica de inicios de la década del noventa estuvo dominada por dos objetivos centrales: 1) la apertura comercial unilateral, en el marco del proceso de integración regional del MERCOSUR; y 2) la consolidación de un proceso de privatización y desregulación de la economía, en el marco de las mencionadas reformas estructurales (Bittencourt, 2006).

En este período se evidenció una fuerte intención de disminuir el gasto público, se modificó la política de contratación de funcionarios públicos y se implementaron los retiros incentivados (Dutra, 2007:15). A diferencia de lo ocurrido en otros países de la región entre 1986 y 1994 la desigualdad del ingreso no cambia sustancialmente.

En relación a la estructura productiva, se destacan dos cuestiones: el desarrollo del área de los servicios y un fuerte proceso de desindustrialización, tal como ocurrió durante el período dictatorial. En este sentido, no pueden dejar de señalarse ciertas continuidades con el ciclo económico de 1973-1990, lo que dificulta la posibilidad de caracterizar la década de los noventa como una "reorientación en el modelo de desarrollo", como sostienen Bértola y Bittencourt. Con respecto al primero de estos procesos el sector de mayor crecimiento del período fue el del transporte y las

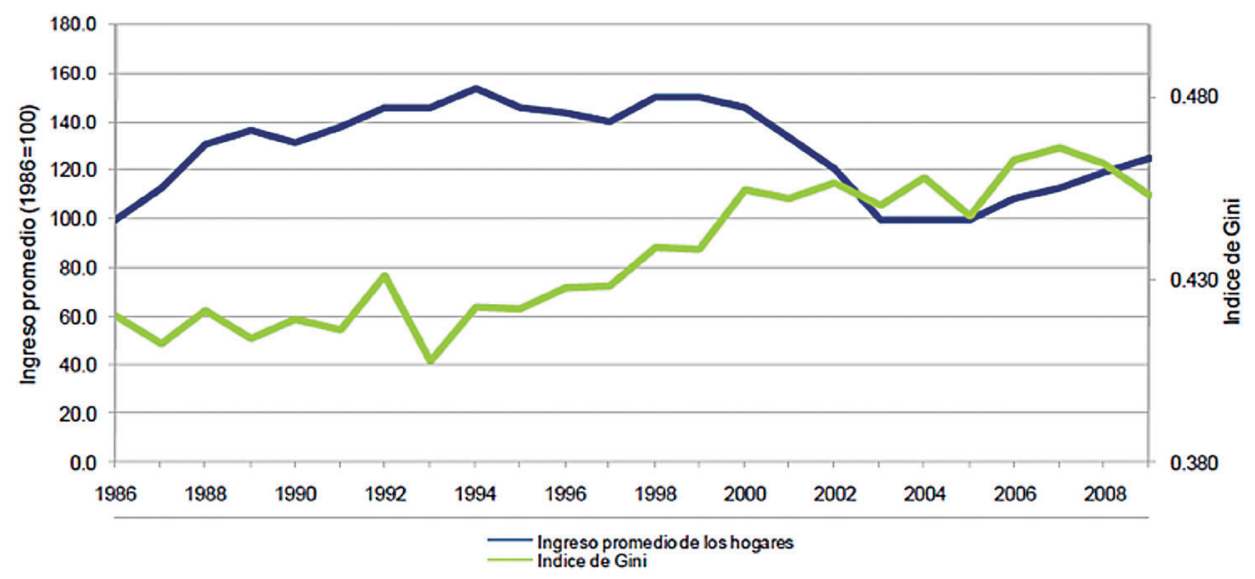

Figura 2. Evolución del índice de Gini y del ingreso per cápita del hogar promedio. 1986-2009. Fuente: Alves, Amarante, Salas, Vigorito, 2012. 
telecomunicaciones. Asimismo, los bienes inmuebles, los servicios a empresas y el comercio, restaurantes y hoteles, experimentaron una notoria expansión en esta década, los dos últimos asociados al desarrollo del turismo (Bértola y Bittencourt, 2005: 317). En síntesis, debido a la demanda interna o a la proveniente de la región, el área de los servicios se posiciona como la más dinámica de la economía en este período.

Con respecto a la segunda cuestión, es evidente que el acelerado crecimiento de la década no se refleja proporcionalmente en el sector industrial. Como puede observarse en la figura 3, la industria permanece con niveles de producción inferiores a los alcanzados en 1987 hasta el 2005. Como señala Bittencourt (2006: 26), "esta reducción del peso del sector industrial en el conjunto de la actividad productiva del país está fuertemente conectada con el aumento del desempleo, que es preexistente a la recesión de 1999 y la crisis de 2002". Por lo que se expresó arriba, queda de manifiesto que la década del noventa se caracterizó por el desarrollo de la producción primaria.

Durante la década de 1990, la economía uruguaya experimentó un proceso sostenido de crecimiento económico. No obstante, la existencia de crecimiento económico no significa necesariamente un mayor desarrollo. Para los autores que comulgan con las ideas de la CEPAL el desarrollo debe entenderse como un proceso multidimensional de mejoramiento de las condiciones de vida de la población a partir de la creación de una estructura productiva homogénea, cuyo núcleo dinámico de acumulación resida en el mercado interno y se encuentre regulado por el Estado (Ferrer, 2007; Guillén, 2007; Sunkel, 2007). Si bien el PBI uruguayo aumenta durante todo el período considerado -lo cual acerca el caso de Uruguay al de Chile y lo aleja de otros casos donde no hubo crecimiento, como el de México (Guillén, 2007)- la heterogeneidad estructural se profundizó junto con la dependencia externa.

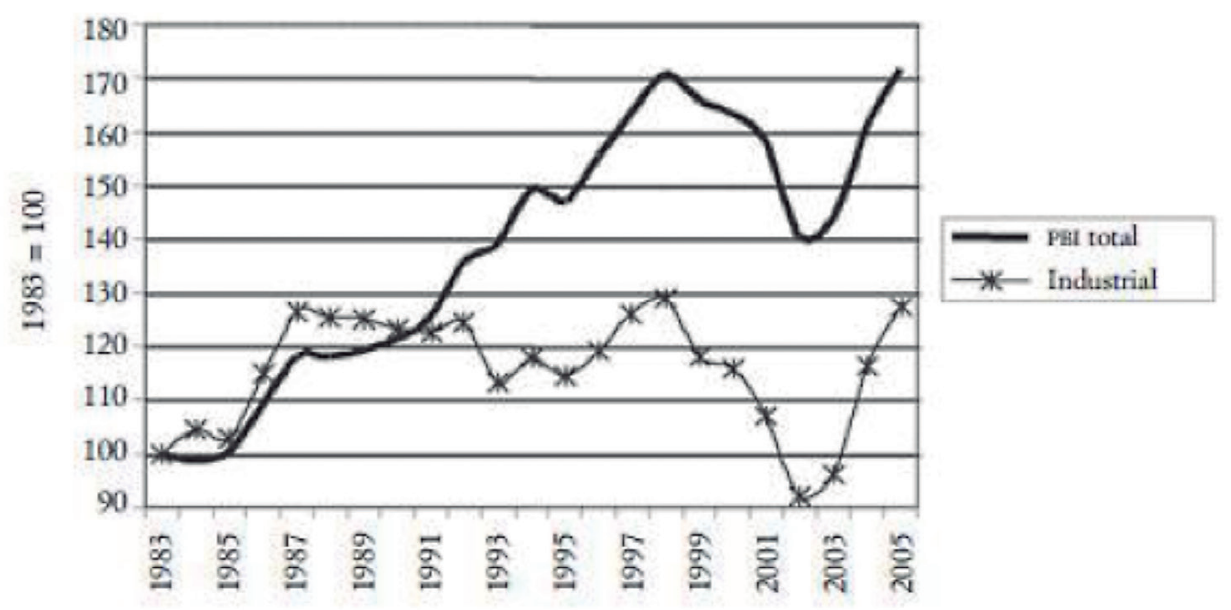

Figura 3. PBI total y PBI industrial. Uruguay (1983-2005). Fuente: Bértola y Bittencout (2005: 316) 
En este sentido el modelo neoliberal reedita varios de los límites que había planteado el viejo modelo agroexportador (Bittencourt, 2006; Guillén, 2007, Sunkel, 2007).

Guillén sostiene que allí donde continuó existiendo algún impulso a la industrialización, se configuró una estructura industrial desarticulada, orientada al consumo de los sectores de altos ingresos y regida por las necesidades de articulación de las empresas transnacionales. El autor concibe a este tipo de desarrollo industrial como un proceso de maquilización, en el seno del cual las industrias se dedican al ensamblaje desvinculándose de los encadenamientos productivos nacionales y profundizando la dependencia tecnológica.

La expansión, desde la sanción de la Ley 15.921 en 1987, de las zonas francas, regímenes territoriales en los que se habilitan condiciones económicas especiales para las actividades de empresas transnacionales, puede analizarse en esta misma dirección. Alfredo Falero (2011 y 2015) sugiere analizar este fenómeno dentro del debate de las economías de enclave que Cardozo y Faletto (2003) propusieron en los años sesenta. La noción de enclave, originalmente aplicada para caracterizar a las producciones bananeras o mineras, sugiere una producción orientada al mercado externo, con baja tasa de reinversión local y fuertemente dependiente de las decisiones de las casas matrices extranjeras. Las zonas francas, son fuertemente conectadas con los espacios centrales de acumulación de las casas matrices y a su vez sufren un proceso de desnacionalización respecto del territorio donde se implantan. Por su parte, la creación de la zona franca montevideana de Zonamérica, a inicios de la década de 1990, constituye un caso paradigmático. Falero concibe este emprendimiento como un "enclave informacional" que reedita la inserción subordinada de los países latinoamericanos en la división internacional del trabajo. En tal sistema, los centros de acumulación retienen la producción científica necesaria para el desarrollo de investigación y de desarrollo, mientras que relegan las tareas de procesamiento de información a la periferia. En estos casos, la inversión extranjera directa se aprovecha de los bajos salariales y de los beneficios impositivos sin impactar sustancialmente en el producto bruto interno.

De este modo, la heterogeneidad estructural se hizo aún más evidente. La inserción en el mercado mundial a partir de las llamadas ventajas comparativas implica nuevamente para América Latina el deterioro de los términos del intercambio. La especialización que se propone se basa en ventajas competitivas estáticas que continúan vinculadas a la superexplotación del trabajo, como los bajos salarios, o a la extracción de materias primas bajo marcos regulatorios flexibles. Por otra parte, esta clase de especialización productiva bajo el modelo del agronegocio conlleva un nocivo impacto en el medio ambiente y un abuso de recursos no renovables.

\section{La "gran crisis" (1999-2004)}

Las consecuencias de las medidas neoliberales se harían sentir con fuerza en la nueva década. Desde enero de 1999 hasta mediados del 2003 Uruguay atravesó 
un período de recesión económica. Tal como lo muestra la figura, el PBI se redujo en un $16 \%$ y la tasa de desempleo aumentó en un $70 \%$. También se acrecentó la inflación, descendieron las exportaciones y la producción manufacturera, lo cual llevó al país al borde de la cesación de pagos (Caetano, 2005). Asimismo la desigualdad, que se había mantenido estable durante la primera parte de los años 1990, comenzará a profundizarse desde 1994 y no se detendrá hasta el 2007. Según Alves, Amarante, Salas y Vigorito (2012) esta evolución se explica fundamentalmente por la desigualdad en los ingresos laborales, los incrementos en las pensiones contributivas, el aumento de los ingresos del capital y los crecientes retornos a la educación.

Fernando Antía (2002 y 2004) señala algunas de las causas de la desaceleración del crecimiento económico de la década de 1990. Por una parte, la contracción del ingreso de capitales hacia América Latina afectó al Uruguay a través de sus efectos en las economías vecinas -a diferencia de Argentina, Uruguay logró sostener el acceso al crédito internacional. Por otra parte, tal como había ocurrido en los años 1980, la crisis se originó en una sobrevaloración de la moneda local en buena medida ocasionada por la decisión oficial de mantener el tipo de cambio en el contexto de la devaluación brasilera de enero de 1999. A los desequilibrios resultantes en la cuenta corriente de la balanza de pagos se les sumaron crecientes desequilibrios fiscales producto de la aplicación de políticas fiscales expansivas, de la retracción de la recaudación impositiva y del endeudamiento externo. Antía señala además algunas causas vinculadas a la producción agropecuaria: la sequía de la primavera de 1999 , el verano del 2000 y la epidemia de aftosa de abril del 2001 que redundó en una mayor contracción de los mercados externos para las exportaciones pecuarias. Así, hacia el 2002 la crisis uruguaya se profundizó en buena medida como reflejo de la crisis argentina, la cual impactó comercialmente al Uruguay al reducirse las exportaciones a ese país -casi el $30 \%$ del total en el 2001- prácticamente en un $70 \%$ en el primer semestre.

No obstante, la crisis del país vecino impactó fundamentalmente en el plano financiero y se expresó mediante el retiro de los fondos de los ahorristas argentinos en las plazas locales. La corrida bancaria se extendió a los ahorristas uruguayos agravando la pérdida de reservas internacionales y motivando una disparada del dólar que pasó de \$27 a \$35.

Hacia fines del 2003 la pobreza creció al 30,9\% y la tasa de desempleo alcanzó el 19\% (Boado y Fernández, 2006). En estos cuatro años emigraron más de 100.000 uruguayos en busca de mejores oportunidades (Caetano, 2005), profundizando un fenómeno que Bértola y Bittencout (2007) denominan "ajuste maltusiano".

Las consecuencias de las políticas neoliberales favorecieron el retorno del debate sobre el desarrollo, mas no la superación del olvido de muchos de los aportes de los años 1960/70. Asimismo, bajo el impulso de Fernando Fajnzylber la CEPAL retomó algunos de sus postulados estructuralistas sin abandonar por completo las propuestas impulsadas por los organismos internacionales. La institución hizo hincapié en la idea de transformación productiva con equidad. Con tal lema se buscaba una mayor apertura comercial orientada hacia la constitución de una competitividad que no se basara en 
las ventajas estáticas, sino en un aumento de la productividad y en un encadenamiento productivo más profundo (Bielschowsky, 2010). A pesar de las similitudes que encuentra Bielschowsky a lo largo de la historia de la CEPAL, sorprende el modo en que el neoestructuralismo cepalino reprodujo acríticamente algunos de los términos instalados por el consenso neoliberal desde los años 1980: la equidad reemplazó a la igualdad, la inclusión olvidó la lucha de clases, desapareció la dependencia y apareció la ciudadanía, comenzó a hablarse de gasto social y de contrato social, y los análisis integrales se perdieron en abordajes focalizados.

\section{LA RECUPERACIÓN ECONÓMICA URUGUAYA Y LOS DEBATES ACTUALES SOBRE EL DESARROLLO (2005-2014)}

Tal como puede constatarse en la figura 4, desde el 2004 hasta la actualidad se asiste a un marcado aumento en el ritmo de crecimiento del PBI. Por tanto, para el 2012 Uruguay era el segundo país latinoamericano con menor proporción de hogares pobres (5,9\% según la CEPAL), superado únicamente por Argentina. Desde el 2007, como puede constatarse en la , la desigualdad, que venía incrementándose desde 1994, comenzó a caer. Entre el 2008 y el 2012 la desigualdad de ingresos se redujo a un 4\% promedio anual, lo que significa la caída más acelerada entre los países de la región.

Las causas de la reversión de esta tendencia son, entre otras, la recuperación del empleo, el incremento del salario mínimo, el descenso de la desigualdad laboral -debido principalmente a la caída de los retornos de la educación- y la instauración de transferencias de ingresos no contributivas por parte del gobierno del Frente Amplio (Alves, Amarante, Salas, Vigorito, 2012). También es importante mencionar en este punto la restauración de la negociación colectiva desde el 2005 después de 13 años. La reforma impositiva realizada por el gobierno frenteamplista en el 2008 tuvo un efecto redistributivo ya que implicó la eliminación del impuesto al salario, la reducción del IVA y del impuesto de contribución financiera a la seguridad social. Otro elemento a destacar en el plano redistributivo es la implementación por parte del Frente Amplio entre abril del 2005 y noviembre del 2007 del Plan de Atención Nacional a la Emergencia Social (PANES). Este plan de transferencia de ingresos estaba condicionado a la asistencia escolar y a los controles en salud, y se focalizaba en los hogares pertenecientes al quintil más bajo. El PANES fue efectivo en la reducción de la brecha de pobreza y de indigencia pero no tuvo un efecto importante en la reducción de la desigualdad. Por su parte, las nuevas Asignaciones Familiares parecen ser responsables de una reducción de dos puntos en el índice de GINI (Alves, Amarante, Salas, Vigorito, 2012).

La recuperación económica que comenzó en el 2005 se sustentó fundamentalmente en el sector agropecuario y en menor medida en la industria manufacturera. El primero de estos sectores se vio beneficiado por la creciente demanda internacional de materias primas, mientras que el segundo creció al amparo de la 


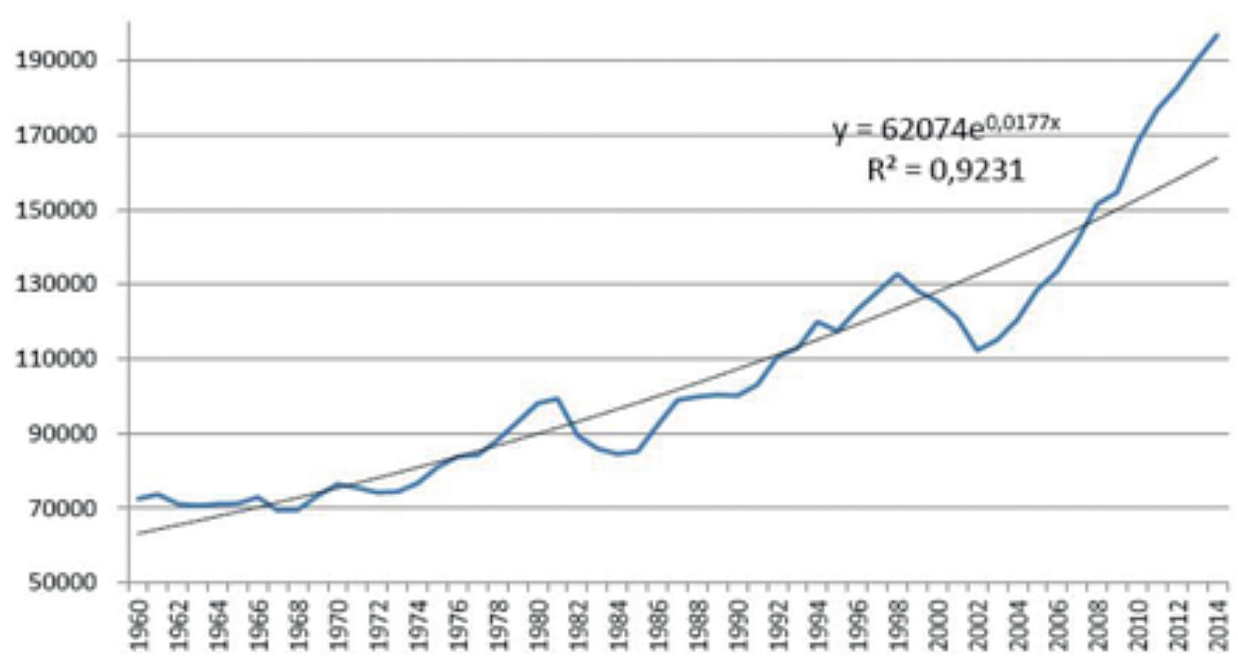

Figura 4. PBI por habitante. 1960-2014. Pesos constantes de 2005. Fuente: Bittencout y Doneschi (2014)

protección cambiaria producto de la devaluación. La recuperación económica se vio reflejada en un aumento de las exportaciones equivalente al 8,8\% en el período 2000-2012. Los cuatro principales rubros de exportación son los que provienen de la industria celulosa, los lácteos, y las carnes. Desde el 2010, China se transformó en el principal comprador de las exportaciones uruguayas.

Las nuevas industrias sustituyeron importaciones o se orientaron a la producción de los componentes industriales de los complejos agroindustriales, como los frigoríficos o las industrias lácteas (Antía, 2004). El sector manufacturero con mayor participación en las exportaciones es la industria celulosa que se ha expandido en el país desde la creación de la planta finlandesa Botnia en el 2004. No obstante, esta reactivación industrial no logró revertir el proceso de desindustrialización iniciado con la apertura comercial de los años 1990.

Según los datos del Banco Mundial, la participación de la industria en el PBI cayó desde un $29 \%$ en 1990 hasta un 17\% en el 2003. La recuperación alcanzó hasta ahora su valor máximo en el 2010 con un $27 \%$, pero al año siguiente y hasta la actualidad la participación de la industria en el PBI se mantiene en un 25\%, cuatro puntos por debajo de los valores de 1990.

Por su parte, la inversión extranjera directa crece desde el 2006 a un ritmo acelerado. La figura 5 muestra que esta inversión se orienta fundamentalmente al sector de los servicios y en menor medida a la industria. Casi el 40\% de la inversión extranjera proviene del MERCOSUR y alrededor del 15\% lo hace desde Europa. Argentina es el principal responsable de la inversión extranjera (30\%), seguido por Brasil (7\%). La mayor parte de la inversión extranjera directa proveniente de Argentina se orienta al sector inmobiliario (Bittencourt y Doneschi, 2014). 


\begin{tabular}{|lcccccc|}
\hline & \multicolumn{2}{c}{$\mathbf{1 9 9 0 - 1 9 9 9}$} & \multicolumn{2}{c}{$\mathbf{2 0 0 4 - 2 0 0 7}$} & \multicolumn{2}{c|}{$\mathbf{2 0 0 8 - 2 0 1 2}$} \\
\hline & Millones US\$ & $\%$ & Millones US\$ & $\%$ & Millones US\$ & $\%$ \\
Sector primario & $\mathbf{1 9 . 0}$ & $\mathbf{1 6 . 4}$ & $\mathbf{2 6 7 . 9}$ & $\mathbf{2 6 . 8}$ & $\mathbf{3 5 4 . 4}$ & $\mathbf{1 5 . 9}$ \\
Industria manufacturera & $\mathbf{2 6 . 5}$ & $\mathbf{2 2 . 8}$ & $\mathbf{3 3 7 . 9}$ & $\mathbf{3 3 . 8}$ & $\mathbf{6 7 1 . 1}$ & $\mathbf{3 0 . 2}$ \\
Alimentos & 11.8 & 10.2 & 30.0 & 3.0 & 154.8 & 7.0 \\
Madera y papel & - & - & 236.2 & 23.6 & 431.0 & 19.4 \\
Quimicos & 4.3 & 3.7 & 56.4 & 5.6 & 33.9 & 1.5 \\
Otros & 10.3 & 8.9 & 15.4 & 1.5 & 51.4 & 2.3 \\
Servicios & $\mathbf{7 0 . 5}$ & $\mathbf{6 0 . 8}$ & $\mathbf{3 9 4 . 8}$ & $\mathbf{3 9 . 5}$ & $\mathbf{1 , 1 9 7 . 5}$ & $\mathbf{5 3 . 9}$ \\
Electricidad, gas y agua & 3.1 & 2.7 & 4.3 & 0.4 & 34.1 & 1.5 \\
Construcción & 4.3 & 3.7 & 205.4 & 20.5 & 716.2 & 32.2 \\
Comercio, restaurantes y hoteles & 44.4 & 38.3 & 57.6 & 5.8 & 181.8 & 8.2 \\
Transporte y comunicaciones & 9.1 & 7.8 & 45.0 & 4.5 & 131.3 & 5.9 \\
Intermediación financiera & s.d. & s.d. & 79.9 & 8.0 & 106.3 & 4.8 \\
Otros servicios & 9.6 & 8.3 & 2.7 & 0.3 & 27.8 & 1.3 \\
Total & 116.0 & $\mathbf{1 0 0}$ & $\mathbf{1 , 0 0 0 . 7}$ & $\mathbf{1 0 0}$ & $\mathbf{2 , 2 2 3 . 0}$ & $\mathbf{1 0 0}$ \\
\hline
\end{tabular}

Figura 5. Distribución sectorial de la IED. Promedios anuales en millones de dólares y porcentajes. Fuente: Bittencout y Doneschi (2014)

\begin{tabular}{lll} 
Moderada & Intermedia & Severa \\
\hline Argentina & Brasil & Bolivia (Estado Plurinacional de) \\
Chile & Colombia & Ecuador \\
Costa Rica & México & El Salvador \\
Uruguay & Panamá & Guatemala \\
& Venezuela (República & Honduras \\
& Bolivariana de) & Nicaragua \\
& & Paraguay \\
& & Perú \\
& República Dominicana \\
\hline
\end{tabular}

Figura 6. Clasificación de los países según su grado de heterogeneidad estructural. Fuente: CEPAL, 2014

\section{Esbozando las características del período actual: Desarrollo dependiente, concentrador e inclusivo}

El caso uruguayo no escapa a la realidad del contexto latinoamericano. El desarrollo del Uruguay continúa mostrando una tendencia hacia la heterogeneidad estructural. Como en el resto de la región, las desigualdades en materia de productividad no se dan solamente entre los distintos sectores de la estructura económica, sino también entre los trabajadores de estos estratos y sectores, cuyas productividades diferentes se asocian a las diferencias de nivel educativo (CEPAL, 2014). Sin embargo, la figura 6 indica que Uruguay es uno de los países de la región con heterogeneidad estructural moderada, tanto si ésta se calcula mediante el 
coeficiente de variación del nivel de productividad de los distintos sectores, como si se la mide en relación con el mercado de trabajo.

En todos los países de la región se observa un rezago en el dinamismo de las estructuras productivas, no solamente respecto del conjunto de países desarrollados sino también frente a otros países en desarrollo -como los del sudeste asiático(CEPAL, 2014: 91). Este dato advierte sobre la debilidad de las políticas igualitarias en Latinoamérica y vuelve a situar el debate del desarrollo en el centro de la escena. Recuperando algunas de sus premisas históricas, la CEPAL (2012) ha ubicado a la igualdad como el principio normativo y el horizonte estratégico del desarrollo. En el documento titulado "Cambio estructural para la igualdad" (CEPAL, 2014) el organismo plantea que el camino para lograr la igualdad es el cambio estructural. Este proceso supone una mayor participación de los sectores intensivos en conocimiento y una diversificación productiva hacia sectores con rápido crecimiento de la demanda interna y externa para evitar desequilibrios de balanza de pagos.

En la figura 7 se puede ver que la industria uruguaya es escasamente dinámica, la participación de los sectores de alta tecnología en el conjunto de las manufacturas es muy reducida y las exportaciones son poco sofisticadas. Si bien algunos de estos datos pudieran haberse modificado en los últimos años -corresponden al $2005 \mathrm{y}$ al 2008- el panorama general da cuenta de una ausencia de cambio estructural, lo cual imposibilita la construcción de una sociedad igualitaria.

Al reducido dinamismo del sector manufacturero se le suma un proceso de concentración y extranjerización en el sector agrícola, principal sostén económico de la economía nacional. Norma Giarraca y Miguel Teubal (2013) describen al

\begin{tabular}{lccc}
\hline & $\begin{array}{c}\text { Participación relativa } \\
\text { de las ingenierías } \\
\text { (IPR) }\end{array}$ & $\begin{array}{c}\text { Productividad }^{\circ} \\
\text { relativa }^{{ }^{b}}\end{array}$ & EXPY $^{c}$ \\
\hline Argentina & 0,40 & 26 & 10,4 \\
Brasil & 0,64 & 12 & 11,2 \\
Chile & 0,17 & 20 & 8,9 \\
Colombia & 0,24 & n.d. & 9,9 \\
México & 0,64 & 20 & 12,5 \\
Uruguay & 0,18 & n.d. & 10,4 \\
\hline Australia & 0,67 & 79 & 12,3 \\
Dinamarca & 0,87 & 73 & 14,0 \\
Finlandia & 0,94 & 101 & 15,0 \\
Noruega & 0,76 & 38 & 10,8 \\
República de Corea & 1,07 & & 14,8
\end{tabular}

Figura 7. Participación relativa de las ingenierías (IPR) ${ }^{2}$ en el valor agregado manufacturero, productividad relativa y EXPY ${ }^{4}$. Países seleccionados. Fuente: CEPAL, 2014. 
modelo económico presente en buena parte de Latinoamérica como un "modelo de agronegocios globales". En este modelo las empresas transnacionales controlan los sectores clave del sistema agroalimentario. En términos generales, la economía tiende a especializarse en pocos productos, volviéndose extremadamente dependiente del mercado mundial. A su vez, la agricultura familiar y los trabajadores rurales son desplazados y suele profundizarse el deterioro ambiental debido a la extensión del monocultivo y a la aplicación de fumigaciones con glifosato. El modelo de agronegocios comienza a extenderse en la región desde de los años 1990, a partir de la entrada del paquete tecnológico para la producción agrícola.

En el Cono Sur la soja ha resultado el principal producto desarrollado bajo tal sistema, aunque no el único. Para el 2012 Uruguay contaba con 1,4 millones de hectáreas sembradas con cultivos biotecnológicos, fundamentalmente soja y maíz (ISAA, 2012), lo que equivale al 14\% de la superficie cultivable según los datos del Banco Mundial. Las causas de "la sojización" se relacionan con múltiples factores, entre otros, la creciente demanda de soja para la producción intensiva de carne en la Unión Europea, China e India, la producción de agrocombustibles, la presencia de capitales especulativos y el desarrollo del paquete tecnológico siembra directa-glifosato-soja RR. Las exportaciones de soja en Uruguay pasaron de US\$1,6 millones en 2001 a US\$ 305 millones a octubre de 2008 y la producción de soja pasó de 10.000 ha en la zafra de 2000/2001 a 462.000 ha en la zafa de 2007/2008, aportando el $75 \%$ del área de cultivos de verano (Oyhantçabal y Narbondo, 2008).

El saldo comercial de la producción de soja es positivo, para la zafra del 2007/2008, el resultado arrojó alrededor de US\$ 220 millones. No obstante, se trata de un complejo agroindustrial fuertemente orientado a la exportación primaria y sujeto a las fluctuaciones del mercado mundial. Alrededor del $70 \%$ de la soja que se produce en Uruguay se exporta hacia a la industria china de harinas y más del 90\% de esta producción se exporta como grano sin procesar. Las fases del complejo de soja que se desarrollan en Uruguay son la agrícola y la de acopio-exportación, lo que da cuenta de que las fases capital-intensivas se despliegan por fuera del país. En este sentido Uruguay se convierte en un país importador de tecnología agrícola, fundamentalmente productos para la fumigación. Pero incluso en la fases que se realizan en el país, el control de la producción dista de ser nacional: los pools de siembra controlan el $57 \%$ de la superficie cultivable y pertenecen mayormente a empresas argentinas, mientras que las empresas responsables de la exportación son grandes transnacionales como Monsanto, Cargill, L. Dreyfus o Nidera, entre otras (Santos, Oyhantçabal y Narbondo, s/f).

A su vez, la sojización bajo el modelo de agronegocios globales conlleva una serie de impactos en la estructura de tenencia de la tierra. Los productores de tipo empresarial, fundamentalmente los empresarios agrícola-ganaderos medios y grandes, se adaptan al boom sojero e incrementan su superficie. Los productores familiares medianos o pequeños capitalistas que no pueden competir con los grandes capitalistas, se convierten en socios de los pools de siembra, apropián- 
dose de la renta del suelo mediante el arrendamiento. Finalmente, los pequeños productores familiares son excluidos y deben migrar hacia los centros urbanos. En síntesis, se constata un avance de la gran empresa capitalista -generalmente extranjera- y una desaparición de los pequeños productores rurales -generalmente nacionales. En efecto, entre el 2000 y el 2007 abandonaron el campo unos 600 productores familiares, que pasaron de ocupar el $17 \%$ al $8 \%$ de la superficie cultivable (Oyhantçabal y Narbondo, 2008).

A partir de los indicadores y los debates contemporáneos sobre el desarrollo que compilamos arriba podríamos arriesgar una caracterización general del proceso de desarrollo actual del Uruguay. En primer lugar, podemos postular que continuamos en presencia de un desarrollo de carácter dependiente. Las dos formas de dependencia descriptas por Santos, la industrial-financiera y la industrial-tecnológica, parecen continuar vigentes cuando analizamos la composición de las exportaciones e importaciones uruguayas. Las exportaciones uruguayas son poco sofisticadas (celulosa, lácteos, carnes y soja) y los sectores de alta tecnología representan un porcentaje muy pequeño dentro de las manufacturas. La industria celulosa es quizás la mayor apuesta de industrialización de los últimos años y busca integrarse productivamente con el desarrollo forestal de mediano aliento en el país. Sin embargo, se trata de un sector de escaso encadenamiento productivo y de bajo dinamismo keynesiano, es decir, con poca capacidad de generación de empleos formales.

En este sentido, la situación de la industria celulosa, con fuerte presencia de inversión extranjera y aprovechamiento de ventajas comparativas estáticas -como la legislación ambiental flexible y los bajos salarios-, evidencia características típicas de las economías de enclave. Las dos plantas de celulosa instaladas por los gobiernos del Frente Amplio operan en zonas francas (Falero, 2015: 228), espacios que, como adelantamos arriba, se configuran como territorios propicios para el despliegue de distintos enclaves. En efecto, durante el primer gobierno del Frente Amplio se habilitaron tres nuevas zonas francas vinculadas a enclaves informacionales (Falero, 2011: 155). La promoción de Uruguay en el extranjero está asociada a la producción estatal de este "mercado de excepciones sociales y territoriales", que pretende favorecer la inversión extranjera directa (Falero, 2011: 156).

Desde esta perspectiva parece difícil argumentar que la presencia de capitales extranjeros constituya un modo de profundizar el desarrollo nacional, tal como aparecía en los debates de los años 1960/70 para los casos de Argentina, Brasil y México. El destino de la inversión extranjera directa -servicios, especialmente actividad inmobiliaria, e industria celulosa- parece confirmar lo antedicho. La gravitación de China, Brasil y Argentina en la economía uruguaya da cuenta del carácter dependiente de este estilo de desarrollo.

Al mismo tiempo, el avance de la sojización en el campo bajo el modelo de agronegocios globales se orienta a la exportación primaria y depende de las fluctuaciones del mercado mundial. Como vimos arriba las fases capital-intensivas del agronegocio se despliegan por fuera del país -lo cual convierte al Uruguay en un país 
importador de tecnología agropecuaria- y los pools de siembra de origen extranjero controlan la parte más jugosa del negocio a nivel local. La sojización expresa un proceso de extranjerización de la tierra que se manifiesta con particular intensidad en Argentina y Brasil pero que viene avanzando también en Uruguay (FAO, 2012). Este tipo de estructura productiva supone además, como hicimos referencia anteriormente, el despliegue de procesos de acumulación por desposesión que se sustentan en el despojo imperial de los bienes comunes.

En el caso uruguayo, la industria no logra convertirse en el eje de la acumulación de capital. Con una productividad reducida y una serie de "ventajas" comparativas estáticas, Uruguay se ubica dentro del conjunto de países que, tal como afirmaba Marini, sustentan su sistema económico en la superexplotación del trabajo mediante la captación de plusvalía absoluta. Como señalaban varios autores en los años 1960/70 este tipo de desarrollo industrial limitado tiende a profundizar la heterogeneidad estructural. Un informe del Instituto Nacional de Estadística de Uruguay (INE, 2005) señala la existencia de tres grandes grupos de empresas con estructuras productivas y rendimientos del capital y del trabajo claramente diferenciados: las pequeñas que abastecen al mercado interno, las medianas que también se orientan al mercado interno y las grandes empresas exportadoras. El despliegue de industrias como la celulosa que poseen bajo dinamismo reproduce la existencia de sectores con niveles de productividad muy distintos. Lo mismo puede decirse en el caso del agronegocio. Como advertía Stavenhagen resulta fundamental estudiar las relaciones que se establecen entre esos sectores.

Otra característica que parece persistir en el desarrollo uruguayo actual es su carácter concentrador. En el campo uruguayo el $60 \%$ de la tierra está en manos de un $10 \%$ de los productores. Entre el 2000 y el 2011 desaparecieron 12.000 explotaciones agropecuarias y el tamaño promedio de las explotaciones aumentó un 80\% (Censo Agropecuario 2011). El modelo de sojización profundiza la tendencia concentradora que se ha manifestado históricamente en el campo uruguayo. También en las manufacturas se expresa el carácter concentrador de este estilo de desarrollo. Para el 2005 el 2\% de las empresas industriales acumulan el $40 \%$ de las remuneraciones sectoriales, el $30 \%$ del personal ocupado, el $43 \%$ del valor agregado, el $45 \%$ del excedente bruto y el $54 \%$ del valor bruto de producción (INE, 2005). En esta línea argumentativa podemos sostener, como lo hacen Bértola, Isabella y Saavedra (2014: 85) que "todos los indicadores muestran que el período en cuestión ha dado muy pocas señales de cambio estructural y que el ciclo expansivo se ha apoyado en actividades tradicionales, que, como ya vimos, se han movido al influjo del movimiento de los precios".

Resulta evidente que el Frente Amplio no ha modificado el modelo de acumulación, antes bien, su política económica ha mostrado un fuerte continuismo respecto de los gobiernos precedentes. Sin embargo, la tercera característica del actual estilo de desarrollo uruguayo evidencia una sutil modificación respecto del camino que se planteó desde los años 1970. Existe una serie de políticas públicas que 
apuntan a modificar el patrón excluyente del desarrollo neoliberal. Iniciativas como la reactivación de las negociaciones colectivas -con el consecuente impulso alcista del salario real-, la reforma impositiva de cuño progresista del 2008, o la instauración de transferencias de ingresos no contributivas -como el PANES y la reforma de Asignaciones Familiares- dan cuenta de esta nueva orientación de la política estatal. Tal como repasamos arriba el efecto de estas iniciativas no ha sido menor y se ha expresado en una importante reducción de la pobreza. En este aspecto, el gobierno del Frente Amplio no se ha mostrado confiado en la teoría del derrame tan en boga en los años 1990. Por el contrario, el gobierno actual se ha encaminado hacia un proceso de redistribución de los excedentes que le ha valido un importante capital político en las últimas elecciones.

Se puede afirmar entonces, que el estilo de desarrollo de este último período histórico en Uruguay muestra un carácter dependiente y concentrador pero a la vez inclusivo. ${ }^{6}$

El panorama descripto empata con la definición de Guddynas de neo-extractivismo progresista. Eduardo Guddynas (2009a) postula la existencia de un "neo-extractivismo progresista" en América Latina. Este estilo de desarrollo implementado por los gobiernos postneoliberales de Argentina, Bolivia, Brasil, Chile, Ecuador, Uruguay y Venezuela se basó en la apropiación de la naturaleza mediante la extracción de materias primas. Tal especialización productiva supuso, como en el extractivismo clásico, una inserción subordinada en el mercado mundial y una serie de impactos socioambientales. La novedad residió en el papel más activo del Estado en la captación y redistribución de los excedentes generados por ese extractivismo mediante una serie de programas sociales focalizados, como el PANES o las Asignaciones Familiares en Uruguay. Para el uruguayo, el éxito de las políticas sociales explica la amnesia recurrente en el tratamiento del neo-extractivismo, que pasa a ser visto por los gobiernos progresistas como necesario y urgente:

\footnotetext{
"Mientras que los debates alrededor del viejo extractivismo incluían el cuestionamiento a las empresas transnacionales, los desiguales términos de intercambio, y la subordinación comercial de América Latina como proveedora de materias primas, bajo el neo-extractivismo hay un giro funcional hacia la globalización.” (Guddynas, 2009a: 220)
}

Estas políticas redundaron entonces en una mayor legitimación de este modelo económico de fuerte carácter dependentista. Frente a lo que conciben como "falsas alternativas" de desarrollo Guddynas y Acosta (2011) proponen pensar en términos de "postdesarrollo", reconstruyendo críticamente las bases conceptuales del desarrollo moderno. Desde esta perspectiva los autores recuperan el concepto de "Buen Vivir" presente en las constituciones de Bolivia y Ecuador y en las demandas y prácticas comunitarias de varios pueblos indígenas latinoamericanos. Las ideas de bienestar pleno, reciprocidad, equilibrio y armonía entre las dimensiones materiales y espirituales, respeto por la naturaleza, consenso, colecti- 
vidad, austeridad, entre otras, integran los sentidos posibles del Buen Vivir. Según Guddynas y Acosta el Buen Vivir renueva la crítica al desarrollo presente en los estudios latinoamericanos pero a su vez la profundiza "ya que se quiere superar la idea convencional del progreso (en su deriva productivista) y del desarrollo (en tanto dirección única y lineal)" (Guddynas y Acosta, 2011: 83).

\section{CONCLUSIONES}

En este trabajo analizamos los principales estilos de desarrollo del Uruguay entre 1974 y 2014 a la luz de los debates sobre el desarrollo latinoamericano. El racconto de estos debates nos sirvió para recuperar una serie de conceptos construidos por las ciencias sociales latinoamericanas. Los postulados acerca de la dependencia, las consideraciones respecto de la heterogeneidad estructural o los planteos acerca del colonialismo interno, articularon una mirada analítica que buscaba teorizar a partir de la realidad de nuestros países. Estos conceptos ingresaron al campo intelectual uruguayo fundamentalmente a través de dos instituciones de distinta inspiración política: la CIDE y el Semanario Marcha. Sin embargo, la CIDE se desarticuló hacia fines de la década de 1960 y la última dictadura cívico-militar terminó con la experiencia de Marcha. De este modo los debates acerca del desarrollo fueron quedando en el olvido y el imaginario latinoamericanista del Uruguay fue clausurado. La difundida imagen de la excepcionalidad uruguaya volvió a escena al compás de la teoría de las ventajas comparativas. Afirmamos entonces que el neoliberalismo resultó en una amnesia respecto del andamiaje conceptual que las ciencias sociales latinoamericanas habían construido años atrás.

Restituyendo la capacidad heurísitca de aquellos conceptos, identificamos la configuración de un estilo de desarrollo dependiente, concentrador y excluyente desde 1973 hasta el 2004. El gobierno de facto se propuso agregar valor a las exportaciones de bienes primarios, desarticulando las políticas de promoción industrial. El crecimiento de la deuda externa y el aumento de los niveles de importaciones, fueron algunas de las consecuencias asociadas a estas políticas.

Pero hemos afirmado que varios elementos de la política económica de la dictadura continuaron vigentes en democracia: la hegemonía del capital financiero, la facultad del Poder Ejecutivo para fijar los precios y los salarios y la libertad internacional de movilidad del capital y del mercado cambiario. Las preocupaciones por el desarrollo dejaron su lugar a los debates sobre la estabilidad monetaria y financiera impulsados por los organismos multilaterales de crédito. A su vez, el área de servicios reemplazó al área industrial, orientada a los sectores de altos ingresos y regida por las empresas transnacionales. En este contexto se profundizó la heterogeneidad estructural y la dependencia uruguaya.

Desde el 2005, los gobiernos del Frente Amplio consiguieron mostrar una mejora de varios indicadores sociales, reduciendo la pobreza y la desigualdad. 
A su vez, pudieron revertir la caída de la actividad económica que caracterizó al período final del gobierno de Jorge Batlle. Sin embargo, la recuperación económica frenteamplista se sustentó fundamentalmente en el sector agropecuario y fue acompañada por un proceso de concentración y extranjerización. Así, se fortaleció un complejo agroindustrial fuertemente orientado a la exportación primaria y sujeto a las fluctuaciones del mercado mundial. Bajo tal modelo, Uruguay ha convertido en un receptor de inversiones extranjeras directas orientadas al desarrollo de actividades de bajo valor agregado. Los casos de la industria celulosa y de la soja ilustran bien el carácter dependiente de este esquema económico.

El neo-extractivismo, los agronegocios globales y la sojización pueden comprenderse como las nuevas formas de la dependencia latinoamericana. Según David Harvey (2005) el "nuevo imperialismo" combina la reproducción ampliada del capital con un continuo mecanismo de acumulación por desposesión. Este mecanismo opera despojando tanto los bienes comunes sociales, fundamentalmente mediante la privatización de empresas y servicios públicos, como los bienes comunes naturales, mediante el extractivismo y otros sistemas como el pago por servicios ambientales. Mediante esta forma de "ajuste espacio-temporal" el sistema capitalista logra evitar las crisis de sobreacumulación, o, al menos, consigue externalizarlas. Desde este punto de vista los éxitos del actual estilo de desarrollo en materia socioeconómica redundan en una peligrosa legitimación del modelo primario-exportador. Por eso, se impone la necesidad de (re)abrir el debate sobre el desarrollo para considerar alternativas más promisorias en el largo plazo.

La construcción de espacios de autonomía frente al contexto de la globalización resulta indispensable. Es cierto que cualquier análisis debe ponderar los márgenes de acción posible dentro de los espacios nacionales, cuestión de peso para un país de 3,4 millones de habitantes ubicado entre las ambiciones de sus grandes socios comerciales. Sin embargo, como afirma Novaro (2015: 40), la dependencia condiciona pero no determina las decisiones de la periferia. Para aumentar la autonomía nacional es necesario articular las luchas del campo popular en función de enfrentar los sectores del capital concentrado, avanzando en una modificación del modelo primario exportador. En cualquier caso, se hace necesario superar la amnesia recurrente del pensamiento latinoamericano recuperando los aportes del conjunto de pensadores que durante los años 1960/70 han reflexionado desde las realidades de sus países con un fructífero diálogo de tradiciones y escuelas de pensamiento.

\section{NOTAS}

1 Es importante señalar que dentro del campo latinoamericano surgieron diversas críticas a la teoría y al concepto de dependencia (ver Beigel, 2006; Kay, 1991; Santos, 1998). Muchos de estos cuestionamientos provinieron del marxismo. Frank, por ejemplo, desconfiaba de un concepto como 
la dependencia que se había puesto de "moda" y que resultaba "igualmente aceptable tanto a las burguesías reformistas como a los marxistas revolucionarios" (Frank citado en Kay, 1991: 106).

2 Índice de participación relativa de los sectores de alta tecnología en el total de las manufacturas, en comparación con la intensidad tecnológica de los Estados Unidos. Corresponde a 2005.

Productividad del trabajo relativa a la de los Estados Unidos. Promedio entre 2001 y 2010.

4 Indicador de sofisticación de las exportaciones, calculado como el promedio ponderado (por la participación de las exportaciones) del indicador PRODY. Este último es el promedio ponderado (por la ventaja comparativa revelada de cada país) del nivel de ingreso per cápita de los países que exportan un cierto bien. Corresponde a 2008.

$5 \quad$ El informe de la FAO puntualiza: "[s]egún los últimos datos estadísticos del estatal Instituto Nacional de Colonización, el 83\% de los campos vendidos en el 2010 (336,000 Ha) fue comprado por extranjeros, incluyendo europeos, brasileños, argentinos, neozelandeses, coreanos y estadunidenses" y agrega que el precio de la tierra se multiplicó por siete en los últimos 10 años en Uruguay.

Preferimos hablar de un desarrollo "inclusivo" en lugar de "igualitario" porque entendemos que las políticas sociales focalizadas sobre las que se asienta la inclusión se orientan a una repartición de bienes más equitativa y razonan sobre el supuesto de la responsabilidad individual del beneficiario. Siguiendo a Cerletti (2010: 5 -6) elegimos reservar el sentido de la igualdad como “...un concepto de la política y, específicamente, de la política de emancipación.” Según este autor la igualdad "[e]s un concepto de la política en primer lugar porque no puede constatarse empíricamente en la realidad, sino que supone intervenir sobre ella." Y continúa: "[1]a igualdad constituye una ruptura con las condiciones reales de existencia, que son siempre "desigualitarias". La decisión por la igualdad implica construir entre todos aquello que nos une, y no universalizar una particularidad hegemónica."

\section{REFERENCIAS}

Alves, Guillermo; Almarante, Verónica; Salas, Gonzalo y Vigorito, Andrea (2012). La desigualdad del ingreso en Uruguay entre 1986 y 2009. Instituto de Economía, UDELAR.

Antía, Fernando (2002). Uruguay 2002: contagio, crisis bancaria y perspectivas. Íconos, Revista de Ciencias Sociales, $\mathrm{n}^{\circ}$ 15, pp. 145-153.

Antía, Fernando (2004). Uruguay: crisis y reactivación económicas en los ochenta y en los dos mil, Montevideo: mimeo.

Beigel, Fernanda (2006). Vida, muerte y resurrección de las "teorías de la dependencia. En AAVV Crítica y teoría en el pensamiento social latinoamericano, Buenos Aires: CLACSO.

Bértola, Luis y Bittencourt, Gustavo (2005). Veinte años de democracia sin desarrollo económico. En Gerardo Caetano (comp.), 20 años de democracia. Uruguay 1885-2005: miradas múltiples, Montevideo: Santillana. 
Bértola, Luis y Bittencout, Gustavo (2007). Los cambios en la estructura productiva para un Uruguay desarrollado. En R. Arocena y G. Caetano (comps.), Uruguay: Agenda 2020, Montevideo: Taurus.

Bértola, Luís; Isabella, Fernando; Saavedra, Carola (2014). El ciclo económico de Uruguay, 1998-2012. Documento On-line, $\mathrm{N}^{\circ} 33$, Montevideo: FCS-UR. Recuperado de: http://cienciassociales.edu. uy/wp-content/uploads/sites/6/2015/05/DT_PHES_No-33-Uruguay-1998-2012.pdf

Bielschowsky, Ricardo (2010). Sesenta años de la CEPAL y el pensamiento reciente. En Ricardo Bielschowsky (ed.) Sesenta años de la CEPAL. Textos Seleccionados del decenio 1998-2008, Buenos Aires: CEPAL-Siglo XXI, pp. 17-90.

Bittencourt, Gustavo (2006). Uruguay 2006: Desarrollo esquivo o ruptura con la historia. En Revista América Latina hoy, $\mathrm{n}^{\circ} 44$, pp. 15-39.

Bittencourt, Gustavo; Galván, Estefanía; Moneira, Cecilia y Vázquez, Daniela (2012). La planificación en el contexto de las estrategias de desarrollo de la posguerra y la experiencia de la CIDE. En G. Bittencourt, E. Galván, C. Moneira y D. Vázquez, Enrique V. Iglesias. Intuición y ética en la construcción de Futuro, Montevideo: Red Mercosur de investigaciones económicas.

Bittencout, Gustavo y Doneschi, Andrea (2014). Capital extranjero en el crecimiento reciente de Uruguay. Ponencia presentada a las XIII Jornadas de Investigación, Setiembre, FCS-UDELAR.

Boado, Marcelo y Fernández, Tabaré (2006). La alegría no va por barrios: ¿qué clases sociales pagaron la gran crisis (2000-2003)?. En E. Mazzei (comp.), El uruguay desde la sociología, Vol. IV, Montevideo, UdelaR.

Caetano, Gerardo (2005). Introducción general. Marco histórico y cambio político en dos décadas de democracia. De la transición democrática al gobierno de izquierda. En G. Caetano (comp.) 20 años de democracia. Uruguay 1985-2005: miradas múltiples, Montevideo: Taurus.

Cardoso, F. Henrique y Faletto, Enzo (2003). Dependencia y Desarrollo en América Latina: ensayo de interpretación sociológica, Argentina: Siglo Veintiuno Editores.

CEPAL (2012). La hora de la igualdad. Brechas por cerrar, caminos por abrir, Santiago de Chile: CEPAL.

CEPAL (2014). Cambio estructural para la igualdad. Una visión integrada del desarrollo, Santiago de Chile: CEPAL.

Cerletti, Alejandro (2010). Igualdad y equidad en las políticas sociales y educativas. En Revista Acontecimiento, Vol. XX, n $38-39$, pp. 95-104.

Dutra, Gustavo (2007). La Economía uruguaya a finales del S. XX e inicios del S. XXI, Montevideo: Universidad de la República, Facultad de Ciencias Económicas y de Administración, Escuela de Administración. Recuperado de: http://www.ccee.edu.uy/ensenian/cateco1/eda/ficha7_08.pdf

Espeche Gilardoni, Ximena (2011). Lo rioplatense en cuestión: el semanario Marcha y la integración (1955-1959). Cuadernos del CILHA, Vol. 12, N 14, pp. 151-170. 
Espeche Gilardoni, Ximena (2010). Uruguay latinoamericano. Carlos Quijano, Alberto Methol Ferré y Carlos Real de Azúa: entre la crisis estructural y la cuestión de la viabilidad nacional (19581968), tesis doctoral en Ciencias Sociales, IDES/UNSAM, mimeo.

Falero, Alfredo (2015). La potencialidad heurística del concepto de economía de enclave para repensar el territorio. NERA, Vol. 18, n²8, edición especial, pp. 223-240.

Falero, Alfredo (2011). Los enclave informacionales de la periferia capitalista: el caso de Zonamérica en Uruguay. Un enfoque desde la sociología, Montevideo: UDELAR.

FAO (2011). El acaparamiento de tierras en América Latina y el Caribe visto desde una perspectiva internacional más amplia, FAO.

Ferrer, Aldo (2007). Globalización, desarrollo y densidad nacional. En Gregorio Vidal y Arturo Guillén R. (coords.), Repensar la teoría del desarrollo en un contexto de globalización. Homenaje a Celso Furtado, Buenos Aires: CLACSO.

Furtado, Celso (1973). Desarrollo y subdesarrollo, Buenos Aires: Eudeba.

Garcé, Adolfo (2002). Ideas y competencia política en Uruguay (1960-1973). Revisando el "fracaso" de la CIDE, Montevideo: Trilce.

Giarraca, Norma y Teubal, Miguel (2013). Las actividades extractivas en la Argentina. En AAVV, Actividades extractivas en expansión: ¿Reprimarización de la economía argentina?, Buenos Aires: Antopofagia.

González Casanova, Pablo (1963). Sociedad plural, colonialismo interno y desarrollo. América Latina, Revista del Centro Latinoamericano de Ciencias Sociales, México D.F., año VI, nº 3.

Guddynas, Eduardo (2009a). Diez tesis urgentes sobre el nuevo extractivismo. Contextos y demandas bajo el progresismo sudamericano actual. En AAVV, Extractivismo, política y sociedad, CAAP-CLAES: Ecuador, pp. 187-225.

Guddynas, Eduardo y Acosta, Alberto (2011). La renovación de la crítica al desarrollo y el buen vivir como alternativa. Utopía y Praxis Latinoamericana, vol. 16, $\mathrm{n}^{\circ}$ 53, pp. 71-83.

Gunder Frank, André (1967) El desarrollo del subdesarrollo. Pensamiento Crítico, n 7, pp. 159-173.

Guillén R., Arturo (2007). La teoría latinoamericana del desarrollo. Reflexiones para una estrategia alternativa frente al neoliberalismo. En Gregorio Vidal y Arturo Guillén R. (coords.), Repensar la teoría del desarrollo en un contexto de globalización. Homenaje a Celso Furtado, Buenos Aires: CLACSO.

Harvey, David (2005). El “nuevo” imperialismo: acumulación por desposesión, Buenos Aires: CLACSO.

Instituto Nacional de Estadística (2005). El sector industrial en el Uruguay. Año 2005: un análisis de su estructura a partir de la cuenta de producción, Uruguay: INE.

Kay, Cristóbal (1991). Teorías latinoamericanas del desarrollo. Nueva Sociedad, nº 113, pp. 101-113. 
Marini, Ruy Mauro (2008a). Dialéctica de la dependencia. En Ruy Mauro Marini América Latina, dependencia y globalización. Fundamentos conceptuales, Bogotá: Siglo del Hombre-CLACSO.

Ministerio de Ganadería, Agricultura y Pesca (2011). Censo Nacional Agropecuario 2011: resultados definitivos, Uruguay: DIEA.

Notaro, Jorge (2010). Estrategia de desarrollo, política económica y actores sociales. Uruguay 19681984. Boletín de Historia Económica, nº 9, pp. 31-40.

Oyhantçabal, Gabriel y Narbondo, Ignacio (2008). Radiografía del agronegocio sojero. Descripción de los principales actores y los impactos socio-económicos en Uruguay, Montevideo: Redes-AT.

Pinto, Aníbal (1970). Naturaleza e implicaciones de la "heterogeneidad estructural" de la América Latina. El trimestre económico, Vol. 37(1), nº 145, México D.F.: Fondo de Cultura Económica.

Rostow, Walt Whitman (1961). The stages of economic growth: a non communist manifesto, Cambridge: Cambridge University Press.

Santos, Carlos; Oyhantçabal, Gabriel y Narbondo, Ignacio (s/f). La expansión del agronegocio agrícola en Uruguay: impactos, disputas y discursos. Ponencia presentada en la Universidad de la República.

Santos, Theotonio dos (1998). La teoría de la dependencia un balance histórico y teórico. En Francisco

Stavenhagen, Rodolfo (1965). Siete tesis equivocadas sobre América Latina. Periódico El Día, 25 y 26 de junio.

Sunkel, Osvaldo (2007). En busca del desarrollo perdido. En Gregorio Vidal y Arturo Guillén R. (coords.), Repensar la teoría del desarrollo en un contexto de globalización. Homenaje a Celso Furtado, Buenos Aires: CLACSO.

Yafee, Jaime (2010). Dictadura y neoliberalismo en Uruguay (1973-1985). Ponencia presentada en las Séptimas Jornadas de Investigación en Historia Económica, 4 y 5 de Agosto, Facultad de Ciencias Sociales, Universidad de la República, Montevideo. 